\title{
Epidemiology and health outcomes associated with hyperkalemia in a primary care setting in England
}

\author{
Laura Horne ${ }^{1}$, Akhtar Ashfaq ${ }^{1}$, Sharon MacLachlan², Marvin Sinsakul ${ }^{1 *}$, Lei Qin ${ }^{3}$, Robert LoCasale ${ }^{4}$ \\ and James B. Wetmore ${ }^{5}$
}

\begin{abstract}
Background: Real-world incidence, clinical consequences, and healthcare resource utilization (HRU) of hyperkalemia $(H K)$ remain poorly characterized, particularly in patients with specific comorbidities.

Methods: Data from the Clinical Practice Research Datalink and Hospital Episode Statistics databases were analyzed to determine incidence of an index HK event, subsequent clinical outcomes, and HRU in the English population. Factors associated with index HK in a primary care setting were also identified for those with an index HK event during the study period (2009-2013) and matched controls.

Results: The overall incidence rate of an index HK event was 2.9 per 100 person-years. Use of renin-angiotensinaldosterone system inhibitors was strongly associated with HK (odds ratio, 13.6-15.9). Few patients (5.8\%) had serum potassium $\left(\mathrm{K}^{+}\right)$retested $\leq 14$ days following the index event; among those retested, $32 \%$ had HK. Following an index HK event, all-cause hospitalization, HK recurrence, and kidney function decline were the most common outcomes (incidence rates per 100 person-years: 14.1, 8.1, and 6.7, respectively), with higher rates in those with comorbidities or $\mathrm{K}^{+}>6.0 \mathrm{mmol} / \mathrm{L}$. Mortality and arrhythmia rates were higher among those with $\mathrm{K}^{+}>6.0 \mathrm{mmol} / \mathrm{L}$. Older age, comorbid diabetes mellitus, and mineralocorticoid receptor antagonist use were associated with HK recurrence. Relatively few patients received testing or prescriptions to treat HK following an event.
\end{abstract}

Conclusions: Severe index HK events were associated with adverse outcomes, including arrhythmia and mortality. Despite this, retesting following an index event was uncommon, and incidence of recurrence was much higher than that of the index event.

Keywords: Chronic kidney disease, Healthcare resource utilization, Hyperkalemia, Incidence

\section{Background}

Hyperkalemia (HK) is a potentially life-threatening electrolyte abnormality typically characterized by elevated serum potassium $\left(\mathrm{K}^{+}\right)$levels $(>5.0 \mathrm{mmol} / \mathrm{L})$ [1]. It is often associated with severe adverse clinical outcomes, including cardiac arrhythmias and mortality, with increasing frequency as $\mathrm{K}^{+}$increases [1,2]. Generally, dietary restrictions are recommended to control $\mathrm{K}^{+}$, and while there are a few acute and chronic drug therapies available to help control $\mathrm{K}^{+}$, these are not widely prescribed and there may be a need for improved treatments. [3]. Sodium polystyrene sulfonate,

\footnotetext{
* Correspondence: marvin.sinsakul@astrazeneca.com

'Global Medical Affairs, AstraZeneca, Gaithersburg, MD, USA

Full list of author information is available at the end of the article
}

the traditional first-line oral therapy, has not been robustly tested in clinical trials for $\mathrm{HK}$, has a variable onset of effect, and is associated with gut necrosis when administered over prolonged periods $[4,5]$. Patiromer, a $\mathrm{K}^{+}$-binding agent recently approved in the United States and Europe, is a potential option for long-term use but must not be taken within $3 \mathrm{~h}$ of other oral medications [6], potentially limiting its use. With few options for long-term control of $\mathrm{K}^{+}$and little consensus on how and when to treat, patients with HK may be undertreated, thereby increasing their risk of HK-related adverse clinical outcomes.

Few studies have evaluated HK incidence or prevalence; those published primarily describe highly selected patient populations. Frequency estimates of HK vary

(c) The Author(s). 2019 Open Access This article is distributed under the terms of the Creative Commons Attribution 4.0 International License (http://creativecommons.org/licenses/by/4.0/), which permits unrestricted use, distribution, and 
based on study designs, including definition of HK and frequency of $\mathrm{K}^{+}$monitoring, and patient characteristics (including comorbidities and medication use) [7, 8]. For example, the HK prevalence among patients with heart failure (HF) in clinical trials evaluating renin-angiotensin-aldosterone system antagonists ranged from 1.4 to $6.0 \%$ depending on the definition of HK used, severity of HF, and medications used [9]. In two studies of patients with chronic kidney disease (CKD), the prevalence of $\mathrm{HK}$, defined as $\mathrm{K}^{+} \geq 5.5 \mathrm{mmol} / \mathrm{L}$, ranged from 3.2 to $31.5 \%[7,8]$.

Availability of high-quality electronic health records enables quantification of HK incidence and the clinical conditions, use of medications, and real-world health consequences associated with $\mathrm{HK}$ in the general population. Here, we report results from a population-based analysis characterizing the incidence rate of $\mathrm{HK}$ and its associated factors, frequency of retesting, clinical consequences, and healthcare resource utilization (HRU) associated with HK among patients receiving healthcare in England.

\section{Methods}

\section{Study design and data sources}

Retrospective analyses, as described in detail below, were conducted using data from the outpatient/primary care Clinical Practice Research Datalink (CPRD) database linked to the inpatient Hospital Episode Statistics (HES) and the Office for National Statistics (ONS) databases. The CPRD is an electronic database of anonymous longitudinal medical records for $>11$ million individuals from $\sim 700$ primary care practices across the United Kingdom [10]. This database captures information such as patient demographics, prescription drug usage, clinical events, laboratory tests, specialist referrals, and hospital admissions and their major outcomes [10]. Independent Scientific Advisory Committee approval (protocol number: 16_217R2) was obtained from the CPRD. The HES database provides information on inpatient care provided at National Health Service hospitals in England [11]. The ONS database contains mortality-related information, including cause of death, for all deaths registered in England and Wales [12].

A cohort analysis was used to determine $\mathrm{HK}$ incidence rate, incidence rates and factors associated with negative clinical outcomes following an index HK event, frequency of HK retesting after the index HK event, and HRU associated with HK. Clinical outcomes of interest included HK recurrence, cardiac arrhythmia, cardiac arrest, HF, acute kidney injury, decline in kidney function, dialysis treatment, all-cause hospitalization, and all-cause mortality. Retesting was evaluated over the 14-day period immediately following the date of the index HK episode. HRU in the 30 days following an index HK event was characterized by the number of laboratory tests, hospitalizations, outpatient visits, specialist referrals, and prescribed medications. Demographics and clinical factors associated with the index HK event were identified using a case-control analysis.

\section{Patient population}

Adults (aged $\geq 18$ years) with an index HK event between January 1, 2009, and December 31, 2013, were identified from the linked CPRD/HES database. The index HK event was defined by at least one of the following: a READ diagnosis code, a laboratory result of $\mathrm{K}^{+} \geq 5.0 \mathrm{mmol} / \mathrm{L}$ in the CPRD, or an International Classification of Diseases, Tenth Revision (ICD-10) diagnosis code in the HES. Patients were excluded from the study for any of the following: an index $\mathrm{K}^{+} \geq 10.0 \mathrm{mmol} / \mathrm{L}$, < 365 days of observation time between the date of the HK event and the current registration or up to standard dates, history of HK events before study start (January 1, 2009), active cancer, or recent history of volume depletion or dehydration (based on a READ diagnosis code). Only patients with $\geq 1$ visit to a general practitioner within the year were included.

\section{Study definitions}

Severity of index HK was classified as follows: $\mathrm{K}^{+} 5.0$ to $\leq 5.5 \mathrm{mmol} / \mathrm{L}$ or CPRD diagnosis code with no corresponding laboratory result, $\mathrm{K}^{+}>5.5$ to $\leq 6.0 \mathrm{mmol} / \mathrm{L}$, or $\mathrm{K}^{+}>6.0$ $\mathrm{mmol} / \mathrm{L}$ or ICD-10 code for HK in the HES database, regardless of $\mathrm{K}^{+}$level (for simplicity, subsequent text will refer to numeric levels). READ and ICD-10 codes used in this analysis are shown in Additional file 1 Table S1. Baseline estimated glomerular filtration rate (eGFR) was calculated using the Modification of Diet in Renal Disease formula [13], using the most recent value for serum creatinine in the 365 days preceding the index HK event. HK recurrence was defined as a second event of elevated $\mathrm{K}^{+}$at any time, provided there was a return to normal $\mathrm{K}^{+}(<5.0 \mathrm{mmol} / \mathrm{L})$. HF, cardiac arrest, and cardiac arrhythmias were defined using ICD-10 codes in the secondary care setting (e.g. HES). Declining kidney function was defined as the presence of diagnostic codes and/or eGFR showing a decline from baseline CKD stage in the CPRD or HES. Acute kidney injury was defined using READ or ICD-10 codes. Provision of dialysis was identified by the presence of a diagnostic or procedure code in the CPRD or HES. All-cause mortality was determined using the date of death in the linked ONS database, with the date preceding the end of study as defined in the CPRD. All-cause hospitalization was determined based on patient record in the HES. For each patient for each event, follow-up began on the day after the index HK event and continued until the earliest of the following: clinical event of interest, patient transferred out of the practice, death, or end of study period (December 31, 2013). 


\section{Statistical analyses}

The incidence rate of an index HK event and each designated clinical outcome was determined for the overall population, stratified by prespecified clinical subgroups (patients with diabetes mellitus, CKD, HF, or hypertension) and index HK event severity. Crude incidence rates were calculated as the number of patients with the designated outcome divided by the total number seeking care and were not adjusted for baseline differences across subgroups. The frequency of HK retesting within 14 days of the index HK event was assessed.

This study used both case-control and cohort analyses to address different study objectives. First, a case-control analysis was conducted to identify factors associated with an index HK event. Each patient with an index HK event in the primary or secondary care setting was eligible to serve as a case. Up to four controls were selected from the CPRD/HES database for each HK case and matched on the care setting of visit (i.e. CPRD or HES), presence of at least one laboratory test of any type on the visit date (CPRD matches only), visit date $( \pm 3$ months), age ( \pm 3 years), time since registration ( \pm 4 years), and sex. Conditional logistic regression analyses were used to evaluate relationships between potential risk factors and HK; adjusted odds ratios (ORs) and 95\% confidence intervals (CIs) are reported. Additionally, a cohort analysis was conducted to identify factors associated with designated clinical outcomes. In the cohort analyses, Cox proportional hazards models were generated to evaluate risk of clinical outcomes and variables identified as significant in the stepwise analysis are presented as adjusted hazard ratios with $95 \%$ CIs, adjusting for all other variables in the model.

Descriptive analysis was performed to evaluate HRU outcomes at 3, 7, and 30 days following an index HK event for the overall population and by HK severity stratum. One inpatient admission, one outpatient visit, all laboratory measurements, and all prescriptions filled for any drug could be included per day.

\section{Results}

A total of 195,178 patients with an index HK event during the study period were analyzed (Additional file 1: Figure S1). Patient demographics and baseline characteristics are shown in Table 1 . Most patients were female (52.1\%), with a mean (standard deviation [SD]) age of 60.6 (16.6) years and mean (SD) eGFR of 80.5 (21.1) $\mathrm{mL} / \mathrm{min} / 1.73 \mathrm{~m}^{2}$. Common baseline comorbidities included hypertension, hyperlipidemia, ischemic heart disease, CKD, and obstructive lung disease. Patients with an index $\mathrm{HK}$ event with $\mathrm{K}^{+}>6.0 \mathrm{mmol} / \mathrm{L}$ had generally higher frequencies of comorbidities, especially ischemic heart disease, arrhythmia, and atrial fibrillation, compared with patients with an index HK event with
$\mathrm{K}^{+} \leq 6.0 \mathrm{mmol} / \mathrm{L}$, although eGFR did not appear to be substantially lower.

Concomitant medications were similar across HK severity strata; key exceptions were loop diuretics and mineralocorticoid receptor antagonists (MRAs), which were roughly two-fold more common among patients with an index HK event with $\mathrm{K}^{+}>6.0 \mathrm{mmol} / \mathrm{L}$ versus $\mathrm{K}^{+} \leq 6.0 \mathrm{mmol} / \mathrm{L}$.

\section{Incidence rates and factors associated with hyperkalemia}

The overall incidence rate of an index HK event was 2.86 per 100 person-years (95\% CI, 2.83-2.89) (Table 2). Most patients experienced an index $\mathrm{HK}$ event with $\mathrm{K}^{+}$ 5.0 to $\leq 5.5 \mathrm{mmol} / \mathrm{L}$ (91.2\%), of which $61.0 \%$ had an event with $\mathrm{K}^{+}$between 5.0 and $5.1 \mathrm{mmol} / \mathrm{L}$. The proportion of patients who had an $\mathrm{HK}$ event with $\mathrm{K}^{+} 5.5$ to $\leq 6.0 \mathrm{mmol} / \mathrm{L}$ and $\mathrm{K}^{+}>6.0 \mathrm{mmol} / \mathrm{L}$ was 7.2 and $1.6 \%$, respectively. The HK incidence rate tended to increase with age, regardless of sex (Fig. 1). Similar age-related trends were observed when patients were stratified by HK severity (Additional file 1: Figure S2).

Factors associated with the index HK event are shown in Table 3. Younger age was associated with increased odds of HK, while use of angiotensin-converting enzyme (ACE) inhibitors, angiotensin II receptor blockers (ARBs), and MRAs, as well as presence of a baseline eGFR value, was strongly associated with the development of HK.

\section{Hyperkalemia retesting}

Overall, only $5.8 \%$ of patients with an index HK event had $\mathrm{K}^{+}$retested within 14 days of the index event (Table 4). Patients with an index HK event with $\mathrm{K}^{+}>6.0 \mathrm{mmol} / \mathrm{L}$ were retested more frequently than those whose index event was $\mathrm{K}^{+} 5.0$ to $\leq 5.5 \mathrm{mmol} / \mathrm{L}$ or $\mathrm{K}^{+}>5.5$ to $\leq 6.0 \mathrm{mmol} / \mathrm{L}$ (55.3, 3.9, and $23.4 \%$, respectively). Among patients retested within 14 days, 32.0\% had a second $\mathrm{HK}$ event with an elevated $\mathrm{K}^{+}$, but this varied only slightly by index $\mathrm{K}^{+}$level: $36.8 \%$ of patients whose index $\mathrm{HK}$ event was $\mathrm{K}^{+}>6.0 \mathrm{mmol} / \mathrm{L}$ had elevated $\mathrm{K}^{+}$upon retesting compared with $29.5 \%$ of patients with an index $\mathrm{HK}$ event with $\mathrm{K}^{+} 5.0$ to $\leq 5.5 \mathrm{mmol} / \mathrm{L}$. Furthermore, a repeat $\mathrm{HK}$ event with $\mathrm{K}^{+}>6.0 \mathrm{mmol} / \mathrm{L}$ was identified in $1.7 \%$ of those with an index HK event with $\mathrm{K}^{+} 5.0$ to $\leq 5.5 \mathrm{mmol} / \mathrm{L}$ and in $19.2 \%$ of those with an index HK event with $\mathrm{K}^{+}>6.0 \mathrm{mmol} / \mathrm{L}$.

\section{Clinical outcomes following an index hyperkalemic event}

The incidence rate of clinical outcomes after an index HK event was higher among patients with a more severe index HK event compared with those with a less severe index event. The largest absolute difference in incidence rates among those with an index $\mathrm{HK}$ event with $\mathrm{K}^{+}>6.0$ $\mathrm{mmol} / \mathrm{L}$ versus $\mathrm{K}^{+} 5.0$ to $\leq 5.5 \mathrm{mmol} / \mathrm{L}$, respectively, was observed for all-cause mortality (12.57 [95\% CI, 11.63- 
Table 1 Patient demographics and baseline characteristics

\begin{tabular}{|c|c|c|c|c|}
\hline & Overall & Serum $\mathrm{K}^{+}$level & Kevent, $\mathrm{mmol} / \mathrm{L}$ & \\
\hline & & $\begin{array}{l}5.0 \text { to } \leq 5.5 \\
(n=177,945)^{\mathrm{a}}\end{array}$ & $\begin{array}{l}>5.5 \text { to } \leq 6.0 \\
(n=14,020)\end{array}$ & $\begin{array}{l}>6.0 \\
(n=3213)^{\mathrm{b}}\end{array}$ \\
\hline Age, years & $60.6 \pm 16.6$ & $60.5 \pm 16.5$ & $60.7 \pm 17.0$ & $63.7 \pm 18.7$ \\
\hline Female & $101,700(52.1)$ & $92,847(52.2)$ & $7174(51.2)$ & $1679(52.3)$ \\
\hline $\mathrm{BMI}, \mathrm{kg} / \mathrm{m}^{2}$ & $28.3 \pm 6.1$ & $28.4 \pm 6.1$ & $27.9 \pm 6.1$ & $27.8 \pm 6.7$ \\
\hline $\mathrm{eGFR}, \mathrm{mL} / \mathrm{min} / 1.73 \mathrm{~m}^{2}$ & $80.5 \pm 21.1$ & $80.6 \pm 20.9$ & $79.7 \pm 22.0$ & $78.2 \pm 23.9$ \\
\hline Smoking status & & & & \\
\hline Never & $100,511(51.5)$ & $91,977(51.7)$ & $6933(49.5)$ & $1606(50.0)$ \\
\hline Current & $36,852(18.9)$ & $33,212(18.7)$ & $2962(21.1)$ & $679(21.1)$ \\
\hline Former & $57,042(29.2)$ & $52,089(29.3)$ & 4059 (28.9) & $888(27.6)$ \\
\hline Unknown & $773(0.4)$ & $667(0.4)$ & $66(0.5)$ & $40(1.2)$ \\
\hline Comorbidities & & & & \\
\hline Hypertension & $98,860(50.7)$ & $90,156(50.7)$ & $6839(48.8)$ & $1865(58.1)$ \\
\hline Hyperlipidemia & $38,245(19.6)$ & $35,009(19.7)$ & $2525(18.0)$ & $711(22.1)$ \\
\hline Ischemic heart disease & $24,886(12.8)$ & $22,486(12.6)$ & $1735(12.4)$ & $665(20.7)$ \\
\hline Myocardial infarction & $10,064(5.2)$ & $9061(5.1)$ & $703(5.0)$ & $300(9.3)$ \\
\hline $\begin{array}{l}\text { Arrhythmia (including } \\
\text { atrial fibrillation) }\end{array}$ & $18,475(9.5)$ & $16,513(9.3)$ & $1364(9.7)$ & $598(18.6)$ \\
\hline Atrial fibrillation & $13,182(6.8)$ & $11,653(6.6)$ & $1033(7.4)$ & $496(15.4)$ \\
\hline Heart failure & $4354(2.2)$ & $3716(2.1)$ & $349(2.5)$ & $289(9.0)$ \\
\hline Cerebrovascular disease & $12,620(6.5)$ & $11,241(6.3)$ & $964(6.9)$ & $415(12.9)$ \\
\hline Peripheral artery disease & $3531(1.8)$ & $3154(1.8)$ & $265(1.9)$ & $112(3.5)$ \\
\hline Diabetes (types 1 and 2) & $24,323(12.5)$ & $22,203(12.5)$ & 1649 (11.8) & $471(14.7)$ \\
\hline Chronic kidney disease & $34,912(17.9)$ & $31,560(17.7)$ & $2457(17.5)$ & $895(27.9)$ \\
\hline Obstructive lung disease & $35,734(18.3)$ & $32,405(18.2)$ & 2607 (18.6) & $722(22.5)$ \\
\hline Liver disease & $7483(3.8)$ & $6600(3.7)$ & $586(4.2)$ & $297(9.2)$ \\
\hline RAAS inhibitor use & & & & \\
\hline Never & $126,475(64.8)$ & $115,215(64.8)$ & 9405 (67.1) & $1855(57.7)$ \\
\hline Current & $59,465(30.5)$ & $54,532(30.7)$ & 4004 (28.6) & $929(28.9)$ \\
\hline Former & $9238(4.7)$ & $8198(4.6)$ & $611(4.4)$ & $429(13.4)$ \\
\hline Concomitant medication & & & & \\
\hline ACE inhibitor & $44,000(22.5)$ & $40,367(22.7)$ & 2989 (21.3) & $644(20.0)$ \\
\hline ARB & $15,495(7.9)$ & $14,253(8.0)$ & $991(7.1)$ & $251(7.8)$ \\
\hline MRA & $3909(2.0)$ & $3336(1.9)$ & $395(2.8)$ & $178(5.5)$ \\
\hline Loop diuretic & $11,493(5.9)$ & $10,126(5.7)$ & $962(6.9)$ & $405(12.6)$ \\
\hline Thiazide diuretic & $14,204(7.3)$ & $13,008(7.3)$ & $927(6.6)$ & $269(8.4)$ \\
\hline NSAID & $18,049(9.3)$ & $16,492(9.3)$ & $1309(9.3)$ & $248(7.7)$ \\
\hline Antibiotic & 3068 (1.6) & $2652(1.5)$ & $309(2.2)$ & $107(3.3)$ \\
\hline
\end{tabular}

Data are given as mean \pm standard deviation or $\mathrm{n}(\%)$

${ }^{a}$ Or Clinical Practice Research Datalink diagnosis code in the absence of laboratory results

${ }^{\mathrm{b}}$ Or Hospital Episode Statistics diagnosis code, regardless of serum $\mathrm{K}^{+}$level

$A C E$ angiotensin-converting enzyme, $A R B$ angiotensin II receptor blocker, $B M I$ body mass index, eGFR estimated glomerular filtration rate, $H K$ hyperkalemia, $K^{+}$ potassium, MRA mineralocorticoid receptor antagonist, NSAID nonsteroidal anti-inflammatory drug, RAAS renin-angiotensin-aldosterone system

13.56] vs 2.51 [95\% CI, 2.46-2.56]) and all-cause hospitalization (28.93 [95\% CI, 27.22-30.72] vs 13.86 [95\% CI, 13.73-13.99]) (Table 5). Incidence rates of renal-associated outcomes at these respective $\mathrm{K}^{+}$levels also differed, with higher rates observed among those with more severe index HK: decline in kidney function (14.61 [95\% CI, 13.46-15.83] vs 6.54 [95\% CI, 6.456.62]), acute kidney injury (4.09 [95\% CI, 3.52-4.72] vs 
Table 2 Incidence of index hyperkalemic event

\begin{tabular}{lll}
\hline & Number of patients with index HK & $\begin{array}{l}\text { Incidence of index HK event } \\
\text { per 100 person-years (95\% Cl) }\end{array}$ \\
\hline $\begin{array}{l}\text { Overall } \\
\text { Serum } K^{+} \text {level during HK event, } \mathrm{mmol} / \mathrm{L}\end{array}$ & 195,178 & $2.86(2.83-2.89)$ \\
$\begin{array}{l}5.0 \text { to } \leq 5.5 \text { or CPRD diagnosis code in the absence } \\
\text { of laboratory results }\end{array}$ & 177,945 & $2.61(2.58-2.63)$ \\
$>5.5$ to $\leq 6.0$ & 14,020 & $0.21(0.20-0.21)$ \\
$>6.0$ or HES diagnosis code, regardless of serum K ${ }^{+}$level & 3213 & $0.05(0.04-0.05)$ \\
\hline
\end{tabular}

$\mathrm{Cl}$ confidence interval, CPRD Clinical Practice Research Datalink, HES Hospital Episode Statistics, HK hyperkalemia, $\mathrm{K}^{+}$potassium

1.18 [95\% CI, 1.15-1.22]), and dialysis (1.55 [95\% CI, $1.23-1.94]$ vs 0.12 [95\% CI, 0.11-0.13]). Rates of the most studied clinical outcomes in patients with diabetes or CKD were approximately double those of the overall study population and were $\sim 3$ - to 6-fold higher in patients with HF compared with the overall study population.

Demographics and clinical factors associated with HK recurrence and other adverse clinical outcomes are shown in Table 6. After age, the presence of comorbid diabetes and use of MRAs at the time of the index HK event were associated with the highest ORs for recurrent HK (1.86 [95\% CI, 1.81-1.91] and 1.74 [95\% CI, 1.64-1.85], respectively); $\mathrm{ACE}$ inhibitor and $\mathrm{ARB}$ use at the time of the index $\mathrm{HK}$ event was also associated with recurrent $\mathrm{HK}$. Having an index $\mathrm{HK}$ event with $\mathrm{K}^{+}>6.0 \mathrm{mmol} / \mathrm{L}$ was associated with all studied outcomes, most strongly with mortality, given that patients with an index HK event with $\mathrm{K}^{+}>6.0 \mathrm{mmol} / \mathrm{L}$ had 3.3 -fold higher odds of death than patients with an index $\mathrm{HK}$ event with $\mathrm{K}^{+} 5.0$ to $\leq 5.5 \mathrm{mmol} / \mathrm{L}$.

\section{Healthcare resource utilization}

In general, the proportion of patients with $\geq 1$ reported HRU following the index HK event increased with severity of the index HK event, with differences apparent as early as 3 days afterward (Fig. 2). Among patients with $\geq 1$ reported HRU, the mean number of laboratory tests increased with the severity of the index HK event, yet only $14.5 \%$ of patients with an index $\mathrm{HK}$ event with $\mathrm{K}^{+} 5.0$ to $\leq 5.5 \mathrm{mmol} / \mathrm{L}$ had any follow-up laboratory tests within a week, compared with $24.5 \%$ of patients with an index HK event with $\mathrm{K}^{+}>5.5$ to $\leq 6.0 \mathrm{mmol} / \mathrm{L}$. Furthermore, only $35.8 \%$ of patients with an index $\mathrm{HK}$ event with $\mathrm{K}^{+}>6.0 \mathrm{mmol} /$ L had any laboratory tests within a week. Similarly, the mean number of hospitalizations generally increased with HK severity at each time point examined. However, HK severity did not appear to be associated with outpatient visits, specialist referrals, or prescriptions.

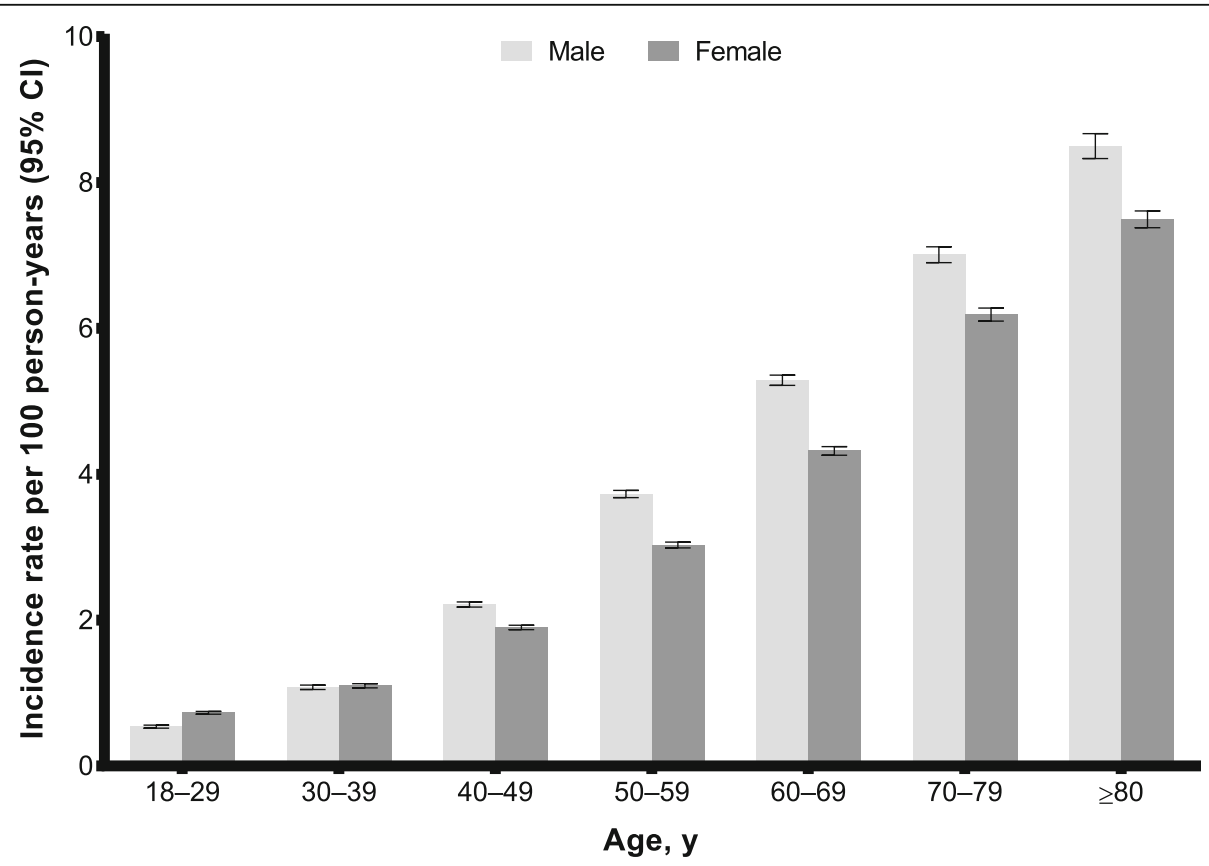

Fig. 1 Incidence of index hyperkalemia event based on age and sex. Error bars show the 95\% confidence interval (Cl) 
Table 3 Factors associated with the index hyperkalemic event

\begin{tabular}{|c|c|c|}
\hline & \multicolumn{2}{|l|}{ Odds ratio $(95 \% \mathrm{Cl})$} \\
\hline & Unadjusted & Stepwise adjusted \\
\hline \multicolumn{3}{|l|}{ Age range, years } \\
\hline $18-29$ & REF & REF \\
\hline $30-39$ & $1.07(1.04-1.10)$ & $0.86(0.83-0.89)$ \\
\hline $40-49$ & $1.15(1.12-1.19)$ & $0.68(0.66-0.71)$ \\
\hline $50-59$ & $1.41(1.37-1.45)$ & $0.68(0.66-0.70)$ \\
\hline $60-69$ & $1.60(1.56-1.65)$ & $0.67(0.65-0.69)$ \\
\hline $70-79$ & $1.76(1.72-1.81)$ & $0.60(0.58-0.62)$ \\
\hline$\geq 80$ & $1.77(1.73-1.83)$ & $0.62(0.59-0.64)$ \\
\hline \multicolumn{3}{|l|}{ Sex } \\
\hline Male & REF & REF \\
\hline Female & $0.89(0.88-0.90)$ & $1.08(1.07-1.10)$ \\
\hline \multicolumn{3}{|l|}{$\begin{array}{l}\text { Presence of measured } \\
\text { baseline laboratory values }\end{array}$} \\
\hline BUN & $1.12(1.05-1.19)$ & $0.70(0.66-0.75)$ \\
\hline eGFR & 31.49 (30.51-32.52) & $29.81(28.84-30.80)$ \\
\hline \multicolumn{3}{|l|}{ Smoking status } \\
\hline Current & $1.05(1.04-1.15)$ & $1.17(1.15-1.18)$ \\
\hline Former & $1.40(1.39-1.26)$ & $1.26(1.24-1.27)$ \\
\hline Never & REF & REF \\
\hline Unknown & $0.72(0.66-1.28)$ & $1.32(1.20-1.44)$ \\
\hline \multicolumn{3}{|l|}{ Comorbidity } \\
\hline Hypertension & $2.29(2.27-2.32)$ & $0.88(0.87-0.90)$ \\
\hline Hyperlipidemia & $1.42(1.41-1.44)$ & $0.85(0.84-0.87)$ \\
\hline Ischemic heart disease & $1.63(1.61-1.66)$ & $0.85(0.83-0.87)$ \\
\hline Arrhythmia (including atrial fibrillation) & $1.33(1.31-1.36)$ & $0.91(0.89-0.93)$ \\
\hline Heart failure & $1.94(1.87-2.02)$ & $0.89(0.84-0.94)$ \\
\hline Cerebrovascular disease & $1.31(1.29-1.34)$ & $0.93(0.91-0.96)$ \\
\hline Peripheral artery disease & $1.71(1.64-1.78)$ & $1.13(1.08-1.19)$ \\
\hline Diabetes (types 1 and 2) & $1.97(1.94-2.01)$ & $0.95(0.93-0.97)$ \\
\hline Chronic kidney disease & $1.69(1.67-1.71)$ & $1.04(1.02-1.06)$ \\
\hline Obstructive lung disease & $0.92(0.91-0.93)$ & $0.95(0.93-0.96)$ \\
\hline Liver disease & $1.13(1.10-1.17)$ & $0.93(0.90-0.96)$ \\
\hline \multicolumn{3}{|l|}{ Concomitant medication } \\
\hline ACE inhibitor & $15.11(14.80-15.43)$ & $13.63(13.31-13.95)$ \\
\hline ARB & $14.56(14.05-15.09)$ & $15.89(15.27-16.54)$ \\
\hline MRA & $17.47(16.17-18.88)$ & $7.77(7.06-8.54)$ \\
\hline Antibiotics & $0.32(0.31-0.33)$ & $0.33(0.32-0.34)$ \\
\hline Loop diuretics & $2.79(2.72-2.86)$ & $1.39(1.34-1.44)$ \\
\hline \multicolumn{3}{|l|}{ Thiazide diuretics } \\
\hline Bendroflumethiazide & $1.86(1.82-1.90)$ & $0.85(0.83-0.88)$ \\
\hline Indapamide & $1.45(1.36-1.54)$ & $0.57(0.52-0.62)$ \\
\hline Hydrochlorothiazide & $2.46(2.26-2.67)$ & $0.83(0.75-0.93)$ \\
\hline
\end{tabular}

$A C E$ angiotensin-converting enzyme, $A R B$ angiotensin II receptor blocker, $B U N$ blood urea nitrogen, $C l$ confidence interval, eGFR estimated glomerular filtration rate, MRA mineralocorticoid receptor antagonist, $R E F$ reference value 
Table 4 Hyperkalemia retesting

\begin{tabular}{|c|c|c|c|c|}
\hline & \multirow{2}{*}{$\begin{array}{l}\text { Overall } \\
(N=194,035)\end{array}$} & \multicolumn{3}{|c|}{ Serum $\mathrm{K}^{+}$level during index $\mathrm{HK}$ event, $\mathrm{mmol} / \mathrm{L}$} \\
\hline & & $\begin{array}{l}5.0 \text { to } \leq 5.5 \\
(n=177,945)^{\mathrm{a}}\end{array}$ & $\begin{array}{l}>5.5 \text { to } \leq 6.0 \\
(n=14,020)\end{array}$ & $\begin{array}{l}>6.0 \\
(n=2070)^{\mathrm{b}}\end{array}$ \\
\hline Patients who had retest within 14 days, n (\%) & $11,342(5.8)$ & $6922(3.9)$ & $3276(23.4)$ & $1144(55.3)$ \\
\hline Patients with HK after retest & $3632(32.0)$ & $2045(29.5)$ & 1166 (35.6) & $421(36.8)$ \\
\hline 5.0 to $\leq 5.5 \mathrm{mmol} / \mathrm{L}^{\mathrm{a}}$ & - & $1782(87.1)$ & $876(75.1)$ & $242(57.5)$ \\
\hline$>5.5$ to $\leq 6.0 \mathrm{mmol} / \mathrm{L}$ & - & $228(11.1)$ & $249(21.4)$ & $98(23.3)$ \\
\hline$>6.0 \mathrm{mmol} / \mathrm{L}^{\mathrm{b}}$ & - & $35(1.7)$ & $41(3.5)$ & $81(19.2)$ \\
\hline
\end{tabular}

${ }^{a}$ Or Clinical Practice Research Datalink diagnosis code in the absence of laboratory results

${ }^{b}$ Or Hospital Episode Statistics diagnosis code, regardless of serum $\mathrm{K}^{+}$level

$H K$ hyperkalemia, $K^{+}$potassium

\section{Discussion}

Using a large comprehensive medical records database from England, we found most index HK events involved only modest increases in $\mathrm{K}^{+}$levels; however, severe $\mathrm{HK}$ occurred more often than might be expected within the general population. Furthermore, HK appeared to be persistent upon retesting and had a graded association with adverse outcomes including hospitalization and death, yet rarely resulted in rapid retesting, even among those with a severe index HK event.

To our knowledge, this is the first population-based study to evaluate the incidence of an index HK event, patterns of retesting $\mathrm{K}^{+}$, and subsequent clinical outcomes in a large general primary-care setting. The observed incidence rate of an index HK event in this study ( 3 per 100 person-years) was generally comparable to that of other studies. A Swedish observational study using a marginally more strict definition of $\mathrm{HK}\left(\mathrm{K}^{+}>5.0 \mathrm{mmol} /\right.$ L) found a crude incidence rate of HK of 5 per 100 person-years [14]. This finding could be due to differences in our study populations, frequency of testing, use of concomitant medications, or prevalence of comorbidities.

Several key factors were associated with index HK in our study. The presence of a baseline eGFR value was strongly associated with HK, likely reflecting prescribers' awareness of its inherent risk associated with kidney dysfunction.

Additionally, use of ACE inhibitors, ARBs, and MRAs, each known to potentially increase $\mathrm{K}^{+}$[14-16], were found to be strong risk factors for HK. Of note, more than half of individuals who had HK were not users of RAAS inhibitors, which may indicate that providers judged these patients to be at disproportionate risk of developing HK, and so did not prescribe these drugs.

In contrast, some characteristics appeared inversely related to index HK development. Interestingly, increased age appeared to reduce the likelihood of an index HK event in this study; the exact reason for this is unknown. Thiazide diuretics, as anticipated, were associated with a lower risk of index HK $[17,18]$; loop diuretics, in contrast, were associated with an increased risk of HK.
While the nature of our study cannot determine why this is the case, the explanation for this finding may be that the patients with the most complex medical conditions or who were judged by their medical providers as being most at risk of HK were also the ones most likely to receive loop, as opposed to thiazide, diuretics.

Strikingly, retesting of $\mathrm{K}^{+}$within 2 weeks of an index HK event was uncommon. While this may be because most index $\mathrm{HK}$ events involved only mildly elevated $\mathrm{K}^{+}$, retesting was far less common than might be expected. Retesting was uncommon even in patients with an index $\mathrm{HK}$ event with $\mathrm{K}^{+}>6.0 \mathrm{mmol} / \mathrm{L}$, with only $55 \%$ retested within 2 weeks of an index HK event. In addition, among those with an index $\mathrm{HK}$ event with $\mathrm{K}^{+}>6.0 \mathrm{mmol} / \mathrm{L}$ who were retested, roughly one in five had $\mathrm{K}^{+}>6.0 \mathrm{mmol} / \mathrm{L}$ when retested within 2 weeks following the event. This is suggestive of both an underappreciation of the importance of $\mathrm{K}^{+}$retesting, especially when $\mathrm{K}^{+}$levels approach or even exceed $6.0 \mathrm{mmol} / \mathrm{L}$, and the likelihood of sustained HK [14]. The lack of prompt $\mathrm{K}^{+}$retesting and the persistence of frank HK could possibly place patients at undue risk of major clinical events. The incidence rate of HK recurrence was particularly high among patients with diabetes, CKD, HF, or hypertension, suggesting that clinicians should pay particular attention to these at-risk groups.

Hospitalization was correlated with the severity of HK. While not all HRU markers were elevated following an HK episode, HK appeared to be associated with hospitalization over short (3 days) and intermediate (30 days) lengths of time. Although the direction of causality is uncertain, HK can be a sign of acute illness (rather than a cause of it), which may portend HK as a particular risk for impending illness and hospitalization, and underscore the need to closely monitor patients with an index HK event. Combined with a comparative lack of $\mathrm{HK}$ retesting and high rate of $\mathrm{HK}$ recurrence after retesting (especially when the index $\mathrm{HK}$ event had $\mathrm{K}^{+}$> $6.0 \mathrm{mmol} / \mathrm{L}$ ), these findings suggest that prudent $\mathrm{HK}$ testing, follow-up, and retesting might identify a patient subgroup at undue risk for adverse events who could benefit from timely interventions in response to HK. 


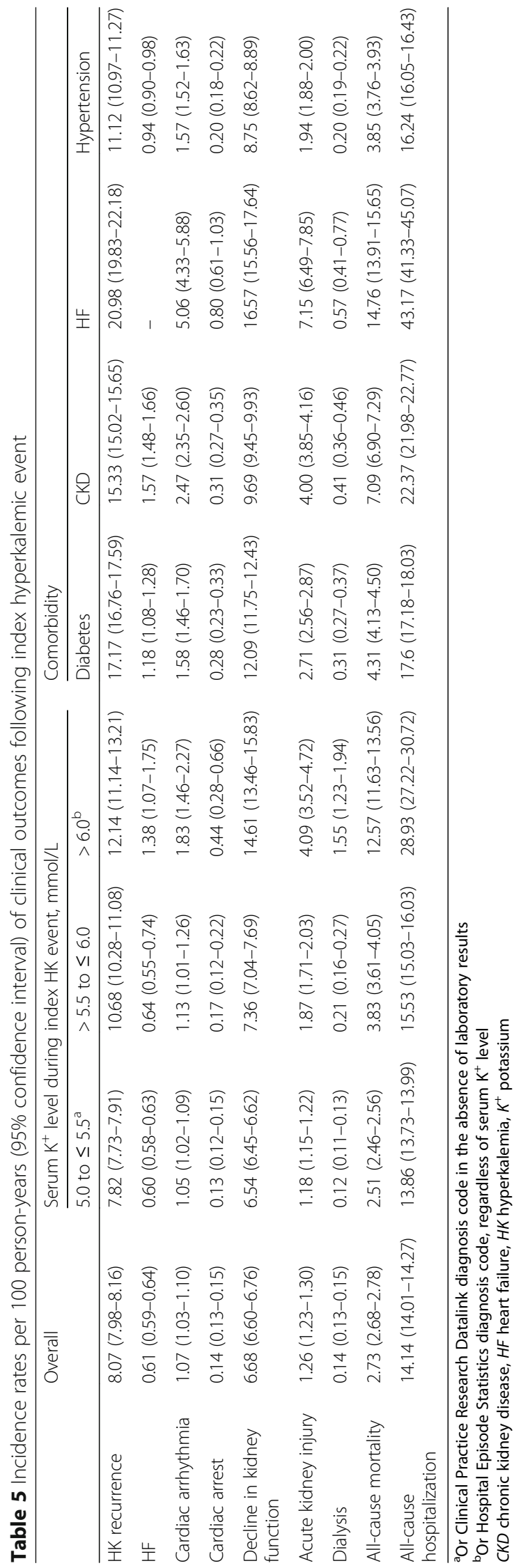


Table 6 Factors associated with hyperkalemia recurrence and other adverse clinical outcomes following an index hyperkalemic event

\begin{tabular}{|c|c|c|c|c|}
\hline & \multicolumn{4}{|c|}{ Stepwise-adjusted odds ratio $(95 \%$ Cl) } \\
\hline & HK recurrence & Cardiac arrhythmia & All-cause hospitalization & Death \\
\hline \multicolumn{5}{|l|}{ Age range, years } \\
\hline $18-29$ & REF & REF & REF & REF \\
\hline $30-39$ & $1.30(1.13-1.48)$ & $1.08(0.58-2.02)$ & $0.96(0.90-1.02)$ & $1.58(0.92-2.71)$ \\
\hline $40-49$ & $1.85(1.64-2.08)$ & $1.52(0.88-2.62)$ & $0.90(0.85-0.95)$ & $3.14(1.95-5.08)$ \\
\hline $50-59$ & $2.29(2.04-2.58)$ & $2.94(1.74-4.96)$ & $0.98(0.93-1.04)$ & $6.19(3.87-9.90)$ \\
\hline $60-69$ & $2.73(2.43-3.07)$ & $6.83(4.08-11.43)$ & $1.15(1.09-1.22)$ & $13.36(8.39-21.27)$ \\
\hline $70-79$ & $3.23(2.87-3.64)$ & $15.52(9.28-25.96)$ & $1.42(1.34-1.50)$ & $30.23(19.00-48.11)$ \\
\hline$\geq 80$ & $3.45(3.06-3.89)$ & $33.18(19.82-55.56)$ & $1.77(1.67-1.88)$ & $91.03(57.21-144.86)$ \\
\hline \multicolumn{5}{|l|}{ Sex } \\
\hline Male & REF & REF & REF & REF \\
\hline Female & - & $0.70(0.65-0.75)$ & - & $0.87(0.83-0.90)$ \\
\hline \multicolumn{5}{|l|}{ Baseline laboratory values } \\
\hline BUN & - & - & $1.50(1.37-1.64)$ & - \\
\hline eGFR & $0.99(0.99-0.99)$ & $1.00(1.00-1.00)$ & $1.00(1.00-1.00)$ & $1.00(1.00-1.00)$ \\
\hline \multicolumn{5}{|l|}{ Smoking status } \\
\hline Current & $1.12(1.08-1.15)$ & $1.22(1.10-1.34)$ & $1.18(1.15-1.21)$ & $1.86(1.76-1.96)$ \\
\hline Former & $1.07(1.04-1.10)$ & $1.04(0.97-1.11)$ & $1.09(1.06-1.11)$ & $1.07(1.02-1.11)$ \\
\hline Never & REF & REF & REF & REF \\
\hline Unknown & $1.04(0.84-1.28)$ & $1.29(0.79-2.12)$ & $0.99(0.85-1.16)$ & $1.91(1.53-2.37)$ \\
\hline \multicolumn{5}{|l|}{ Comorbidity } \\
\hline Hypertension & $1.23(1.19-1.27)$ & $1.11(1.03-1.19)$ & - & - \\
\hline Hyperlipidemia & $1.04(1.01-1.07)$ & $0.86(0.80-0.93)$ & - & $0.79(0.76-0.83)$ \\
\hline Ischemic heart disease & $1.15(1.11-1.18)$ & $1.42(1.31-1.54)$ & $1.28(1.25-1.31)$ & $1.12(1.07-1.17)$ \\
\hline Arrhythmia (including atrial fibrillation) & $1.10(1.06-1.14)$ & - & $1.30(1.27-1.34)$ & $1.33(1.27-1.39)$ \\
\hline Heart failure & $1.10(1.03-1.17)$ & $1.32(1.12-1.56)$ & $1.14(1.08-1.20)$ & $1.38(1.29-1.48)$ \\
\hline Cerebrovascular disease & $1.04(1.00-1.08)$ & $1.27(1.16-1.40)$ & $1.18(1.14-1.22)$ & $1.60(1.53-1.68)$ \\
\hline Peripheral artery disease & $1.10(1.03-1.17)$ & $1.29(1.11-1.50)$ & $1.31(1.25-1.38)$ & $1.43(1.32-1.54)$ \\
\hline Diabetes (types 1 and 2) & $1.86(1.81-1.91)$ & - & $1.08(1.05-1.11)$ & $1.27(1.21-1.33)$ \\
\hline Chronic kidney disease & $1.19(1.15-1.23)$ & - & $1.08(1.05-1.11)$ & $1.09(1.05-1.15)$ \\
\hline Obstructive lung disease & $1.06(1.03-1.09)$ & $1.36(1.26-1.46)$ & $1.28(1.25-1.31)$ & $1.36(1.31-1.42)$ \\
\hline Liver disease & $1.21(1.15-1.28)$ & $1.47(1.26-1.72)$ & $1.50(1.44-1.56)$ & $2.01(1.87-2.17)$ \\
\hline \multicolumn{5}{|l|}{ Concomitant medication } \\
\hline ACE inhibitor & $1.27(1.23-1.31)$ & - & $0.90(0.88-0.92)$ & $0.77(0.74-0.80)$ \\
\hline ARB & $1.16(1.12-1.21)$ & - & $0.92(0.89-0.95)$ & $0.66(0.62-0.70)$ \\
\hline MRA & $1.74(1.64-1.85)$ & $1.36(1.15-1.61)$ & $1.15(1.10-1.22)$ & $1.23(1.14-1.32)$ \\
\hline Loop diuretics & $1.10(1.06-1.15)$ & $1.78(1.61-1.97)$ & $1.33(1.28-1.38)$ & $1.87(1.78-1.97)$ \\
\hline Bendroflumethiazide & $0.90(0.86-0.93)$ & $1.17(1.06-1.30)$ & $0.96(0.92-0.99)$ & - \\
\hline Indapamide & $0.84(0.75-0.94)$ & - & - & - \\
\hline NSAID & $1.21(1.17-1.25)$ & - & $1.30(1.27-1.34)$ & - \\
\hline
\end{tabular}


Table 6 Factors associated with hyperkalemia recurrence and other adverse clinical outcomes following an index hyperkalemic event (Continued)

\begin{tabular}{|c|c|c|c|c|}
\hline & \multicolumn{4}{|c|}{ Stepwise-adjusted odds ratio $(95 \% \mathrm{Cl})$} \\
\hline & HK recurrence & Cardiac arrhythmia & All-cause hospitalization & Death \\
\hline Antibiotics & - & - & $1.57(1.48-1.66)$ & $1.50(1.38-1.65)$ \\
\hline \multicolumn{5}{|c|}{ Serum $\mathrm{K}^{+}$level during index HK event, mmol/L } \\
\hline 5.0 to $\leq 5.5^{\mathrm{a}}$ & - & - & - & - \\
\hline$>5.5$ to $\leq 6.0$ & $1.39(1.33-1.44)$ & $1.07(0.96-1.21)$ & $1.10(1.06-1.13)$ & $1.41(1.33-1.50)$ \\
\hline$>6.0^{\mathrm{b}}$ & $1.34(1.23-1.47)$ & $1.47(1.18-1.83)$ & $1.63(1.54-1.74)$ & $3.27(3.02-3.54)$ \\
\hline
\end{tabular}

${ }^{a}$ Or Clinical Practice Research Datalink diagnosis code in the absence of laboratory results

${ }^{\mathrm{b}}$ Or Hospital Episode Statistics diagnosis code, regardless of serum $\mathrm{K}^{+}$level

$A C E$ angiotensin-converting enzyme, $A R B$ angiotensin II receptor blocker, BUN blood urea nitrogen, $C l$ confidence interval, eGFR estimated glomerular filtration rate, $H K$ hyperkalemia, $K^{+}$potassium, MRA mineralocorticoid receptor antagonist, NSAID nonsteroidal anti-inflammatory drug, REF reference value

Several study design and database limitations should be considered when interpreting these findings. The CPRD captures data among patients seeking healthcare in a primary care setting and may not fully represent the healthcare status of all patients; this study may not be generalizable to populations outside of England because of inherent differences in populations, treatment strategies, and services. Although the CPRD/HES database is well validated $[10,19]$, the potential for misclassified or nonspecific ICD-10 codes, diagnosis codes, and/or laboratory data exists and may lead to over- or under-reporting of HK events and other clinical outcomes, especially because clinical diagnoses were not verified by chart review. One study found the sensitivity of ICD-10 codes for diagnosing HK to be low
(14.6\% at hospital admission), which may contribute to under-reporting of HK events [20]. However, the likely effect of this would be to underestimate the risk associated with HK. As noted earlier, laboratory data are not available in the HES database; therefore, if severe cases were not coded correctly, they would have been excluded from this analysis. Incidence of HK may also be misreported because this analysis primarily relied on laboratory findings of $\mathrm{HK}$ in the CPRD which likely included instances of spurious HK due to hemolysis. Further, the data sources could not account for previously unobserved occurrences of HK which might have obfuscated comorbidities at baseline, as it may be unclear if these conditions are a result of untreated HK. In addition, this analysis did not include emergency care

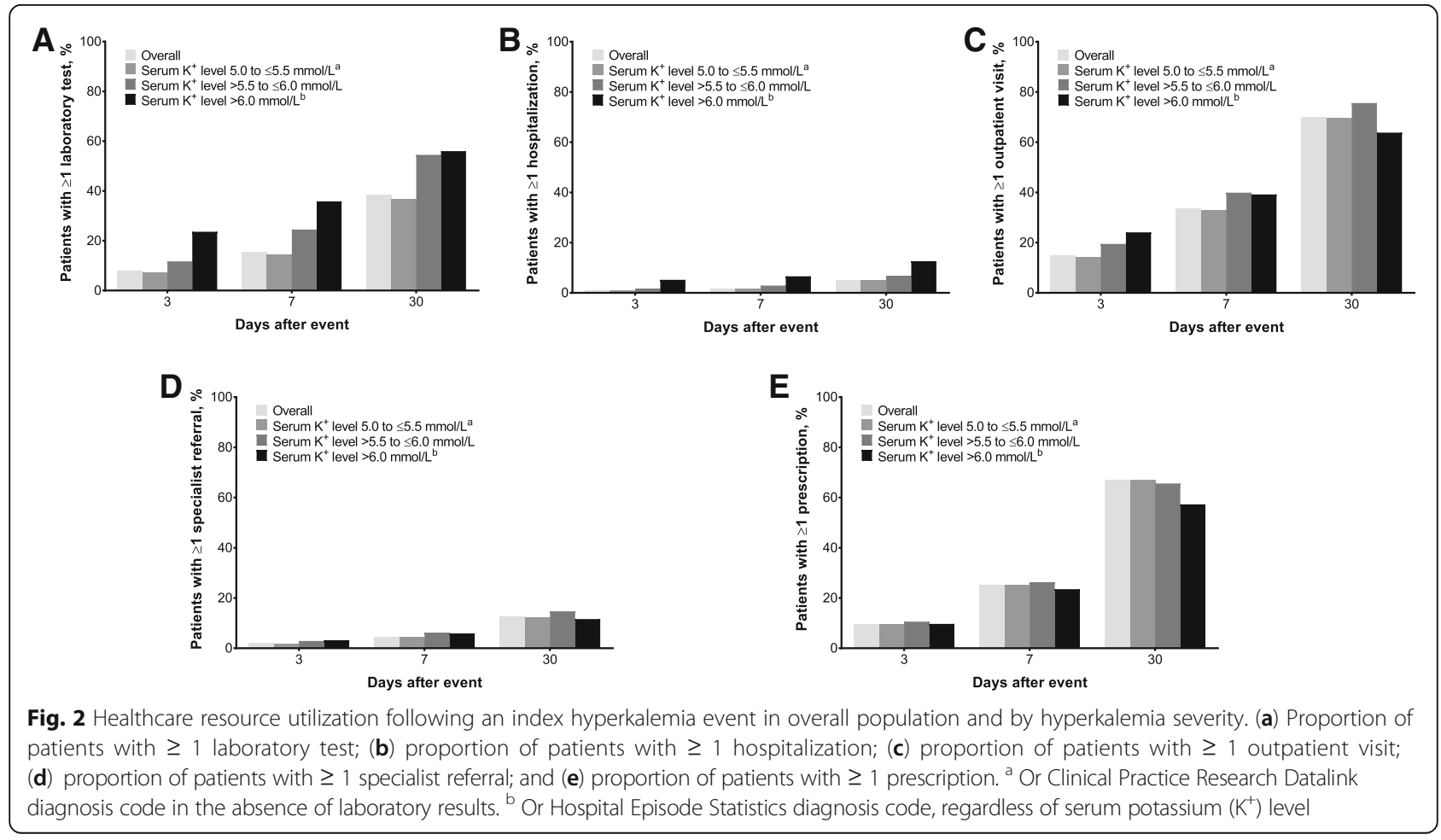


data, which may contribute to potential undercapturing of HK diagnoses given that repeat testing may have occurred in an emergency setting. The incidence of repeat testing may have been further affected by mis-diagnoses and inaccurate $\mathrm{K}^{+}$levels due to hemolysis. The analysis may also be limited because of infrequent measurements of $\mathrm{K}^{+}$. Finally, this study cannot assess whether there is a causal relationship between HK and outcomes following HK events.

\section{Conclusions}

This study is the first to quantify $\mathrm{HK}$ incidence, $\mathrm{K}^{+}$testing patterns, and outcomes associated with $\mathrm{HK}$ in a primary care setting in England, and findings suggest that current attention to HK in general practice may be suboptimal. Although patients who experienced an index HK event, particularly with $\mathrm{K}^{+}>6.0 \mathrm{mmol} / \mathrm{L}$, were more likely to experience a second occurrence of $\mathrm{HK}$ as well as adverse clinical outcomes, repeat testing was not common, and it is unclear whether directed treatment for HK was administered. While causality could not be determined in this study, an association between HK and adverse clinical outcomes was identified, suggesting that underdiagnosis and undertreatment of HK may increase the risk of adverse clinical outcomes. As well-tolerated therapies for the long-term management of HK become readily available, the benefits of more frequent testing of $\mathrm{K}^{+}$and restoring normokalemia may become apparent. More research is needed in at-risk patients with frequently monitored $\mathrm{K}^{+}$levels whose $\mathrm{K}^{+}$is controlled to normal levels to fully understand $\mathrm{HK}$ and its consequences.

\section{Additional file}

Additional file 1: Table S1. Codes used to define adverse events in this analysis. Figure S1. Selection of patients for inclusion in the study. Figure S2. Hyperkalemia incidence according to age and sex based on (A) serum potassium $\left(\mathrm{K}^{+}\right) 5.0$ to $\leq 5.5 \mathrm{mmol} / \mathrm{L}$ or Clinical Practice Research Datalink diagnosis code in the absence of laboratory results, (B) serum $\mathrm{K}^{+}>5.5$ to $\leq 6.0 \mathrm{mmol} / \mathrm{L}$, and (C) serum $\mathrm{K}^{+}>6.0 \mathrm{mmol} / \mathrm{L}$ or Hospital Episode Statistics diagnosis code, regardless of serum $\mathrm{K}^{+}$level in the initial hyperkalemic event. (PDF $159 \mathrm{~kb}$ )

\section{Abbreviations}

ACE: Angiotensin-converting enzyme; ARBs: Angiotensin II receptor blockers; Cl: Confidence interval; CKD: Chronic kidney disease; CPRD: Clinical Practice Research Datalink; eGFR: Estimated glomerular filtration rate; HES: Hospital Episode Statistics; HF: Heart failure; HK: Hyperkalemia; HRU: Healthcare resource utilization; ICD-10: International Classification of Diseases, Tenth Revision; $\mathrm{K}^{+}$: Potassium; MRAs: Mineralocorticoid receptor antagonists, ONS: Office for National Statistics; OR: Odds ratio; SD: Standard deviation

\section{Acknowledgements}

Christine O'Leary, PharmD, BCPS, and Disha Patel, PhD, of inscience Communications, Springer Healthcare (New York, NY, USA), and Jennifer L. Giel, PhD, on behalf of inScience Communications, Springer Healthcare, provided medical writing support, which was funded by AstraZeneca. Mary Beth DeYoung of AstraZeneca critically reviewed the manuscript.

\section{Funding}

This analysis was supported by AstraZeneca. The authors were provided independence in designing the study; data collection, analysis, and interpretation; and preparing the manuscript for publication.

\section{Availability of data and materials}

The datasets analyzed during the current study are available from the corresponding author on reasonable request.

\section{Authors' contributions}

$\mathrm{LH}, \mathrm{AA}, \mathrm{LQ}, \mathrm{RL}$, and JBW contributed to the study conception and/or design. $\mathrm{LH}, \mathrm{AA}, \mathrm{SM}$, and MS contributed to the data analysis and interpretation. All authors contributed to the drafting and/or revising of the manuscript, provided intellectual content of critical importance to the work described, and gave final approval of the version to be published.

\section{Ethics approval and consent to participate}

All research undertaken using data obtained from the Clinical Practice Research Database (CPRD) is approved by, as appropriate, an ethics committee, a scientific committee, and the National Information Governance Board Ethics and Confidentiality Committee. The study protocol (protocol number: 16_217R2) was approved by the Independent Scientific Advisory Committee from the CPRD. The CPRD adheres to all applicable UK and European laws, National Health Service Guidelines, and other guidelines governing research. All CPRD data is anonymized, and additional compliance safeguards put in place include, but are not limited to, Charters, Privacy Enhancing Technologies, and legal arrangements, among others.

\section{Consent for publication}

Not applicable.

\section{Competing interests}

$\mathrm{LH}$ is a consultant to AstraZeneca and owns AstraZeneca stock. AA was a full-time employee of AstraZeneca at the time of study conduct. SM is an employee of Evidera who provides consultancy services to AstraZeneca. MS and LQ are employees and stockholders of AstraZeneca. RL was an employee of AstraZeneca and owned AstraZeneca stock at the time of the study conduct. JBW serves on the speakers' bureau for OPKO Renal.

\section{Publisher's Note}

Springer Nature remains neutral with regard to jurisdictional claims in published maps and institutional affiliations.

\section{Author details}

${ }^{1}$ Global Medical Affairs, AstraZeneca, Gaithersburg, MD, USA. ${ }^{2}$ Real World Evidence, Evidera, London, UK. ${ }^{3}$ Health Economics and Payer Analytics, AstraZeneca, Gaithersburg, MD, USA. ${ }^{4}$ Real World Evidence, AstraZeneca, Gaithersburg, MD, USA. ${ }^{5}$ Chronic Disease Research Group and Division of Nephrology, Hennepin County Medical Center, Minneapolis, MN, USA.

Received: 6 April 2018 Accepted: 8 February 2019

Published online: 06 March 2019

\section{References}

1. Kovesdy CP. Management of hyperkalaemia in chronic kidney disease. Nat Rev Nephrol. 2014;10:653-62.

2. National Kidney Foundation. Clinical update on hyperkalemia: a chronic risk for CKD patients and a potential barrier to recommended CKD treatment. 2014. https://www.kidney.org/sites/default/files/02-10-6785_HBE Hyperkalemia_Bulletin.pdf. Accessed 16 Jan 2018.

3. National Kidney Foundation. Hyperkalemia: survey of awareness and experience among adults with CKD. 2017. https://www.kidney.org/sites/ default/files/HyperkalemiaReport1.pdf. Accessed 16 Jan 2018.

4. Beccari MV, Meaney CJ. Clinical utility of patiromer, sodium zirconium cyclosilicate, and sodium polystyrene sulfonate for the treatment of hyperkalemia: an evidence-based review. Core Evid. 2017;12:11-24.

5. Harel Z, Harel S, Shah PS, Wald R, Perl J, Bell CM. Gastrointestinal adverse events with sodium polystyrene sulfonate (Kayexalate) use: a systematic review. Am J Med. 2013;126:264 e9-24.

6. Veltassa (patiromer). US prescribing information. Redwood City, CA: Relypsa, Inc.; 2016. 
7. Einhorn LM, Zhan M, Hsu VD, Walker LD, Moen MF, Seliger SL, et al. The frequency of hyperkalemia and its significance in chronic kidney disease. Arch Intern Med. 2009;169:1156-62.

8. Sarafidis PA, Blacklock R, Wood E, Rumjon A, Simmonds S, Fletcher-Rogers J, et al. Prevalence and factors associated with hyperkalemia in predialysis patients followed in a low-clearance clinic. Clin J Am Soc Nephrol. 2012;7: 1234-41.

9. Desai AS. Hyperkalemia in patients with heart failure: incidence, prevalence, and management. Curr Heart Fail Rep. 2009;6:272-80

10. Herrett E, Gallagher AM, Bhaskaran K, Forbes H, Mathur R, van Staa T, et al. Data resource profile: clinical practice research datalink (CPRD). Int J Epidemiol. 2015;44:827-36.

11. National Health Service (NHS). Hospital Episode Statistics. https:/digital.nhs. uk/data-and-information/data-tools-and-services/data-services/hospitalepisode-statistics. Accessed 15 June 2017.

12. National Health Service (NHS). Linked HES-ONS mortality data. https://digital. nhs.uk/data-and-information/data-tools-and-services/data-services/inkedhes-ons-mortality-data. Accessed 15 June 2017

13. Levey AS, Coresh J, Greene T, Marsh J, Stevens LA, Kusek JW, et al. Expressing the modification of diet in renal disease study equation for estimating glomerular filtration rate with standardized serum creatinine values. Clin Chem. 2007:53:766-72.

14. Nilsson E, Gasparini A, Ärnlöv J, Xu H, Henriksson KM, Coresh J, et al. Incidence and determinants of hyperkalemia and hypokalemia in a large healthcare system. Int J Cardiol. 2017;245:277-84.

15. Ben Salem C, Badreddine A, Fathallah N, Slim R, Hmouda H. Druq-induced hyperkalemia. Drug Saf. 2014;37:677-92.

16. Weir MR, Rolfe M. Potassium homeostasis and renin-angiotensinaldosterone system inhibitors. Clin J Am Soc Nephrol. 2010;5:531-48.

17. Palmer BF. Regulation of potassium homeostasis. Clin J Am Soc Nephrol. 2015;10:1050-60

18. Wile D. Diuretics: a review. Ann Clin Biochem. 2012;49:419-31.

19. Herrett E, Thomas SL, Schoonen WM, Smeeth L, Hall AJ. Validation and validity of diagnoses in the general practice research database: a systematic review. Br J Clin Pharmacol. 2010;69:4-14.

20. Fleet JL, Shariff SZ, Gandhi S, Weir MA, Jain AK, Garg AX. Validity of the international classification of diseases 10th revision code for hyperkalaemia in elderly patients at presentation to an emergency department and at hospital admission. BMJ Open. 2012;2:e002011.

Ready to submit your research? Choose BMC and benefit from:

- fast, convenient online submission

- thorough peer review by experienced researchers in your field

- rapid publication on acceptance

- support for research data, including large and complex data types

- gold Open Access which fosters wider collaboration and increased citations

- maximum visibility for your research: over $100 \mathrm{M}$ website views per year

At $\mathrm{BMC}$, research is always in progress.

Learn more biomedcentral.com/submissions 